\title{
Conjunctivo Corneal Intraepilheleal Neoplasia-Invasive Squamous Cell Carcinoma of Middle Age Group People
}

\author{
M Anwarul Kader ${ }^{1}$, A K M Shahidur Rahman Tarafder $^{2}$, K Gholam Faruq $^{3}$
}

\begin{abstract}
Conjunctivo corneal intra epithelial neoplasia and invasive squamous cell carcinoma is rare but not uncommon it involve older patient ${ }^{1 \cdot}$ Here we get two cases of middle age group patient suffering from invasive squamous cell carcinoma. Intra epithelial neoplasia is a precancerous condition may turn into invasive squamous cell carcinoma when invade the basement membrane. These are vision threatening even life threatening condition. The slightest sign of recurrence with invasive squamous cell carcinoma the eye must be excised and if recurrence takes place, the orbit must be exenterated and radiation therapy should be given ${ }^{2}$. So early diagnosis and proper management is important. In this article two cases of well differentiated invasive squamous cell carcinoma confirmed by histopathological report of middle aged group people and their management are presented. There is no recurrence after five years of treatment. So invasive squamous cell carcinoma may occur in middle age group people and histopathological test may require in all suspicious cases of abnormal growth of limbal conjunctiva specially pterygium like growth with a different presentation.
\end{abstract}

TAJ 2011; 24(1): 51-53

\section{Introduction}

Conjunctivo-corneal invasive squamous cell carcinoma is not uncommon in our country in USA it is the most common conjunctival malignancy ${ }^{2}$. It is much more prevalent in central Africa associates with the epidermic human immuno deficiency virus infection and involve young adult ${ }^{1}$. Ultraviolet $\beta$-radiation (290-320nm) may be important in its pathophysiology ${ }^{4}$. Human Papilloma Virous (HPV) type 16 and 18 may also be responsible for tumour development ${ }^{5}$. It is formerly known as carcinoma in situ. Bowens disease may transform into invasive squamous cell carcinoma when invade the basement membrane. The tumour commonly arise in the inter palpebral area of the perilimbal conjunctiva.
The growth may be nodular gelationus flat superficial leucoplakia or diffuse invasive fashion it is slowly growing tumour sometimes coexist with pinguecula and pterygia. Long term neglected cases may spread into globe or orbit. The treatment option include tumour removal with or without cryotherapy, radiotherapy and topical chemotherapy. Previous report reveals high recurrence rate after simple excision.

\section{Patients and Method}

At (Eye out patient department) of Rajshahi Medical College Hospital from January 2004 to December 2005. Thirty five (35) cases of pterygium and limbal growth operation was done and three cases, which were suspicious with a 
different presentation (nodular and highly vascular) after surgical excision sent for histopathological test. Histopathological report shows, two patients are well differentiated squamous cell carcinoma and other one is inflammatory. First two cases are reported.

\section{Case report Case-1}

In March 2004 Md. Selimuddin age 43 years come in the Eye Out Patient Department (EOPD) of Rajshahi Medical College Hospital with redness, foreign body sensation, mild watering and blurring of vision fore more than one year. He was treated with steroid drop and ointment previously. $\mathrm{He}$ attend at the eye OPD for proper management. On examination, a whitish nodular mass surrounded by blood vessels starting from 3'oclock position at the limbus, invading the periphery of the cornea was found, his visual acuity was FC 6/18 of the affected eye and $6 / 12$ of the other eye. The mass was excised after application of surface and infiltration anaesthesia at the conjunctival sac. The growth was excised starting at the conjuctival site with a rim of $2 \mathrm{~mm}$ to $3 \mathrm{~mm}$ healthy conjuctiva and proceeded towards the cornea with blunt dissection. Thermal cautery was done at the surgical end of the conjuctiva. Excised tissue sent for histopathological report shows well differentiated invasive squamous cell carcinoma. The patient was very much anxious and referred to department of oncology. Radiotherapy was given locally. The patient was followed 2 monthly upto 1 year and his visual acuity was not detoriate. No recurrence was found. The patient healthy for last 5 years no any ocular complain about that growth was given.

\section{Case-2}

In October $2004 \mathrm{Md}$. Tosiqul Islam of 39 years came at the Eye OPD at Rajshahi Medical College Hospital with a complain of redness, swelling and irritation of Right eye. On examination, the feature was similar to that of pterygium but blood vessels are more congested and there was a nodular growth at the limbus at 9 O'clock position but not extend to the cornea. His visual acuity was 6/9 both eye, the mass was excised with a rim of 2 to 3 $\mathrm{mm}$ healthy conjuctiva. The excised tissue was sent for histopathology. Steroid and antibiotic drop was given for three weeks and systemic antibiotic was given for 7 days. Histopathological report shows the conjuctival invasive squamous cell carcinoma and followed upto one year. No recurrence was occurred.

\section{Discussion}

Conjunctivo corneal epithelial malignancies are more common in elderly male patients ${ }^{2}$. But in this article both the patient were under 43 years old male patients. Male are predominance probably due to increased occupational exposure to sunlight ${ }^{5}$. Ultraviolet light probably are more important in the cause of these malignant lessions ${ }^{3}$. The importance of HPV type 16 and 18 in pathophysiology of conjunctival carcinoma is uncertain ${ }^{6}$. In this article the patients were managed by surgical excision and thermal cautery at the margin of the conjunctiva and radiation was given in one case. But there are different modalities of treatment are noted in different article. Excision with intra operative control of surgical margins and adjunctive cryotherapy results in good tumour control rate. Topical and subconjuctival interferon alpha $2 \mathrm{~b}$ is a valuable treatment option for conjunctival intra epithelial neoplasm ${ }^{8}$. Topical mitomycin c $0.04 \%$ appears to be a safe and effective therapy conjunctivo corneal squamous cell carconoma?. Orbital invasion is reported $12-16 \%$ invasive case ${ }^{5}$. Recurrence of conjunctivo corneal epithelial malignancies depend on the status of surgical margin. Simple excision of conjunctival intraepithelial or invasive neoplasia is associated with $24-50 \%$ of recurrence rate ${ }^{5}$. Follow up examination for longer than 12 months are necessary as the mean time to recurrence has been reported between 8 and 12 months $^{6}$.

\section{Conclusion}

Conjuctivo corneal invasive squamous cell carconoma is rare but not uncommon. It is more common in elderly patient and middle age group may also be sufferer. So each and every suspicious cases whatever may be the age group from young adult to elderly patient excision should be done carefully and histopathological test should be done, so that early diagnosis and management would be possible which can prevent loss of vision even morbidity and mortality of the patient. 


\section{References}

1. Devid L. Estly John M. Sparrow. Oxford text book of Ophthalmology 1999:1: 343-345.

2. Grossniklaus HF. Green WR.I uckenbach $M$ et al., Conjunctival lesions in adult carcinoma 1987, 6: 86-116.

3. Eng. H-L; Lin, -T-M; et al. Failure to detect human Papillomavirus DNA is malignant epithelial neoplasma of conjunctiva by polymerase chain reaction. Am-JClin-Pathol. 2002, Mar; 117(3); 429-36.

4. Lee GA. Williams G. Hirst LW, et al., Risk factors in the development of ocular surface epithelial dysplasia, Opthalmology 1994; 101:360-4.
5. Eric JC. Campbell TJ. Conjunctival and corneal intraepithelial neoplasia. Ophthalmology 1986; 93176-83.

6. Mural Tunc, Devron H Char, et al. Intraepithelial and invasive squamous cell carcinoma of the conjunctiva; analysis of 60 cases $\mathrm{Br}$. J. Ophthalmol 1999; 83: 98-103.

7. Shields -C-L: Naseripour. M: et al., Topical mitomycin $\mathrm{C}$ for extensive, recurrent conjunctivo corneal squamous cell carcinoma. Am-JOphthalmol. 2002 May; 133(5):601-6.

8. Kobayashi-a; Yoshita-T et al., Successful management of conjunctival intraepithelial neoplasia by interferon alpha 2b. Jpn-J-Ophthalmol. 2002 MarApr; 46(2) 215-7. 